\title{
Changes in age-specific seroprevalence of Japanese encephalitis virus and impact of Japanese encephalitis vaccine in Korea
}

\author{
Byung Ok Kwak, $M D^{1}$, Young Jin Hong, $\mathrm{MD}^{2}$, Dong Hyun Kim, $\mathrm{MD}^{2}$ \\ ${ }^{1}$ Department of Pediatrics, Hallym University Kangnam Sacred Heart Hospital, Seoul, Korea; ${ }^{2}$ Department of Pediatrics, Inha University School of Medicine, Incheon, \\ Korea
}

The Japanese encephalitis (JE) virus is the leading cause of vaccine-preventable encephalitis in Asia. Since the introduction of a universal JE vaccination program and urbanization of Korea, the incidence of JE has dramatically decreased in Korea. However, recent JE cases have occurred, predominantly among unvaccinated adults and with a shift in age distribution. Here we aimed to review the changes in age-specific JE seroprevalence over time and discuss the implications of JE vaccination programs in Korea. Following the last epidemic in 1982-1983, mandatory vaccination for all children aged 3-15 years was conducted annually until 1994. However, JE has reemerged, predominantly affecting unvaccinated adults aged 40 years or older and demonstrating a shift in age distribution toward older populations. The age-specific seroprevalence of the JE virus in Korea has changed noticeably over time. Seropositivity in children and adolescents increased from $10 \%-59 \%$ in the 1970s to $90 \%-92 \%$ in the 1980s after the implementation of the JE vaccination program and increased further to $98 \%$ in 2012. No age-specific difference in the seroprevalence of $\mathrm{JE}$ was found, and appropriate levels of immunity to JE were maintained for all age groups. Continuous surveillance of the seroprevalence of JE is essential to establish a proper immunization policy in Korea.

Key words: Japanese encephalitis vaccine, Korea, Neutralizing antibodies, Seroprevalence

\section{Key message}

Since the introduction of a universal Japanese encephalitis (JE) vaccination program and urbanization, the incidence of JE has dramatically decreased in Korea. However, recent JE cases have occurred, predominantly among unvaccinated adults and with a shift in age distribution. Continuous surveillance of the seroprevalence of JE is required to establish a proper immunization policy in Korea.

\section{Introduction}

Japanese encephalitis (JE) is the leading cause of viral encephalitis in Asia. ${ }^{1)} \mathrm{JE}$ viruses are transmitted by bird-biting mosquitoes, primarily those from the Culex genus, and maintained through zoonotic cycles between pigs and wild birds. Humans are incidental or dead-end hosts in the JE transmission cycle.. ${ }^{2)} \mathrm{JE}$ has spread throughout Asia, but national immunization programs (NIPs) or urban development in the 1960s led to its nearelimination in some Asian countries, including Japan, Korea, Taiwan, and Singapore. However, it remains endemic in much of the rest of Asia. ${ }^{3)}$ There is no specific antiviral treatment for JE, and vaccination is the single most important control measure. ${ }^{2)} \mathrm{JE}$ was first reported in 1947 in Korea and remained endemic there until the $1980 \mathrm{~s} .{ }^{4,5)}$ The mouse brain-derived formalin-inactivated Nakayama JE vaccine was first introduced in $1967 .{ }^{6}$ In response to a major JE epidemic, the JE vaccine was included in the NIP in 1985, which led to a dramatic decrease in the number of reported cases. ${ }^{4,7}$ This review investigated the changes in the age-specific prevalence of JE-neutralizing antibodies (NTAbs) over time as well as the impact of JE vaccination programs on reducing the burden of disease in Korea.

\section{Epidemiology}

The JE virus, a mosquito-borne flavivirus, is the main cause of viral encephalitis in many Asian countries. JE has historically remained endemic throughout most of Asia and parts of the western Pacific (Fig. 1). ${ }^{1,8)}$ However, recent evidence of locally acquired JE has been identified even in Africa. ${ }^{9)} \mathrm{JE}$ is more common in rural and suburban areas, where rice cultivation and pig farming exist. ${ }^{1,8)}$ An estimated 67,900 JE cases occur annually (overall incidence: $1.8 / 100,000$ population), including $51,000(75 \%)$ cases in children aged $0-14$ years (incidence: 5.4/100,000). ${ }^{8}$ In some developed Asian countries, including Japan, Taiwan, and Korea, the incidence of JE has decreased over 


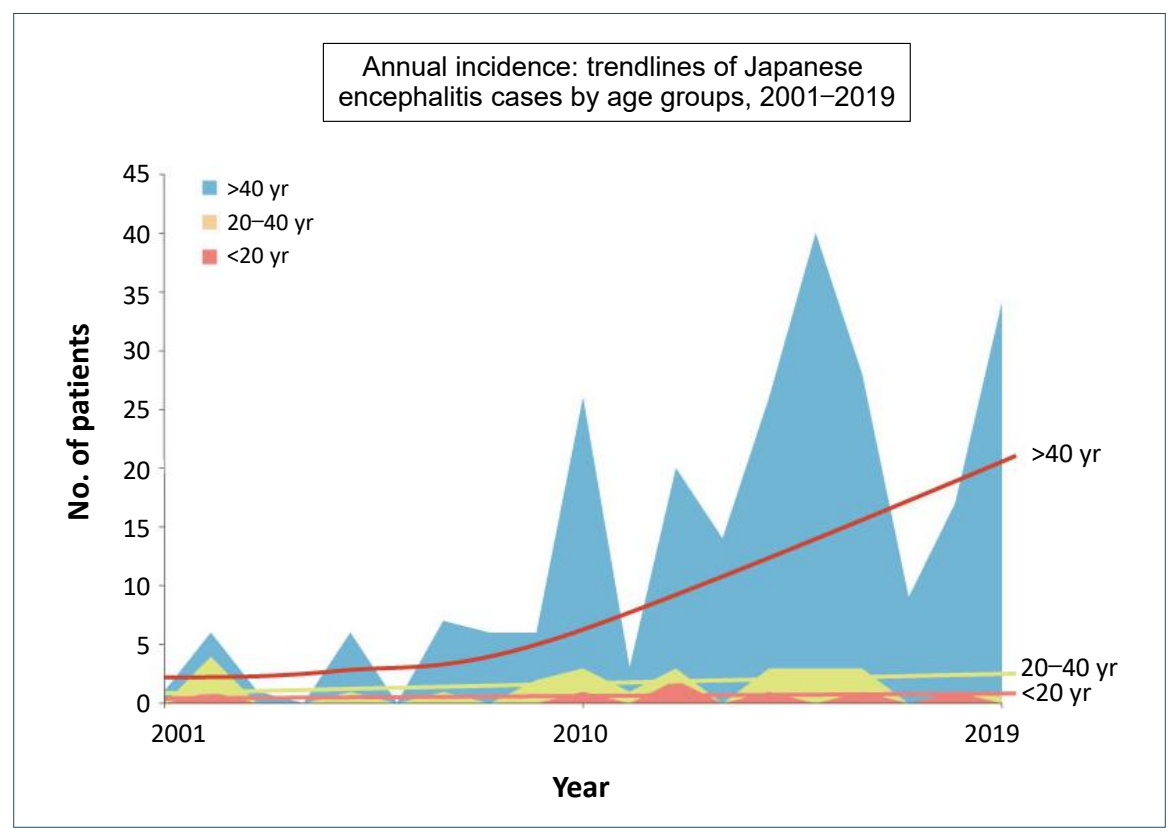

Graphical abstract

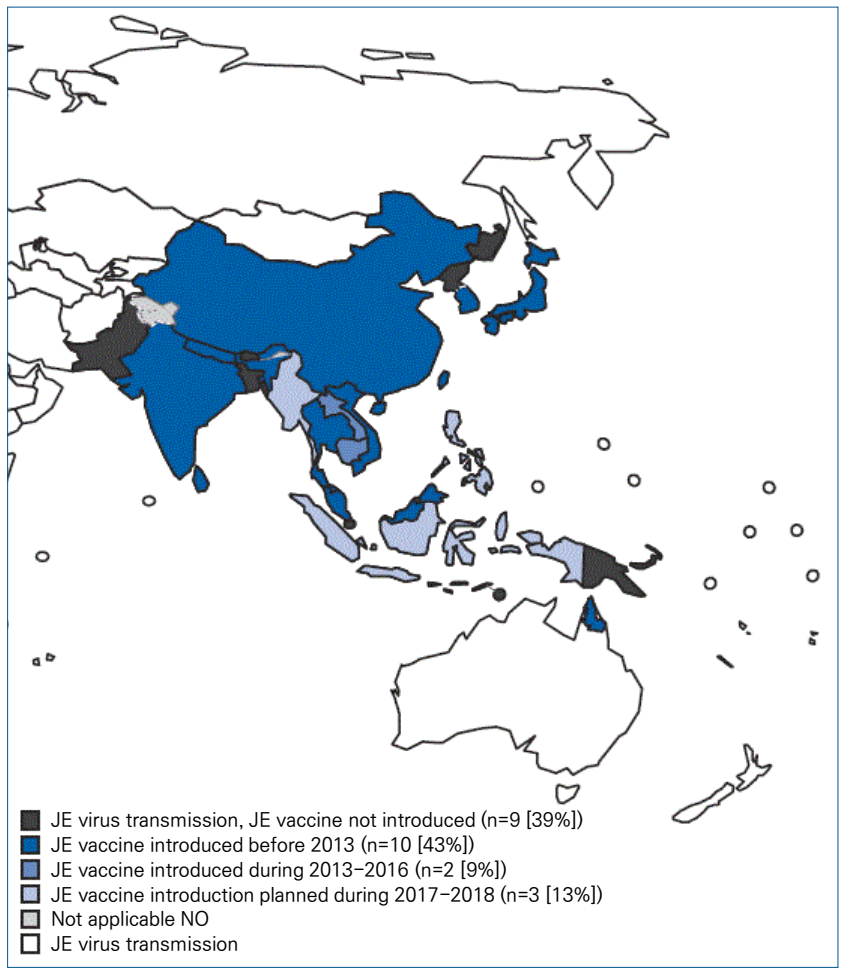

Fig. 1. Areas at risk for Japanese encephalitis (JE) virus transmission and JE vaccine introduction. Adapted from Heffelfinger et al. MMWR Morb Mortal Wkly Rep 2017;66:579-83. ${ }^{3)}$

several decades; currently, fewer than 10-20 cases are typically reported annually.

Use of the JE vaccine has dramatically decreased the number of pediatric JE cases in these countries. In addition, a number of environmental factors, including improved sanitation, reductions in land cultivation, widespread use of agricultural pesticides, and centralization of pig farms, probably contributed to the decline. ${ }^{1)}$ In countries with childhood JE vaccination programs, the age distribution of cases has shifted from children to adults, particularly the elderly. ${ }^{1,4,10-12)}$ In Japan, the age shift in JE patients was reported from bimodal peak age groups of young children and elderly people to a predominance of adults. In 1982-2004, $361 \mathrm{JE}$ cases were reported, and most of the patients were 40 years old or older, with a peak in the 60- to 69-year age group. Moreover, unvaccinated populations were predominantly affected by JE. ${ }^{11)}$ A similar trend has been observed in Taiwan. Pediatric JE cases have been prevented by immunization, and the age distribution of cases has shifted from young children to adults. ${ }^{12,13)}$ Waning vaccine-induced immunity, age-related host factors, and reduced natural boosting by urbanization may have contributed to an increased risk of JE in adults. ${ }^{1)}$

In Korea, the first documented clinical case of JE was recorded in 1947, and JE remained endemic until the 1980s (Fig. 2). Since the JE vaccine was first introduced in Korea in 1967, the number of confirmed cases decreased from 12,055 cases (mean annual incidence, $6.04 / 100,000$ persons) in 1961-1967 to 3,783 cases (mean incidence, 0.67/100,000) in 1968-1983.6) After the last epidemic in 1982-1983, mandatory vaccination for all children aged 3-15 years was conducted annually until 1994.") As a result, the prevalence of JE infections has markedly decreased, and only 55 cases (mean incidence of $0.004 / 100,000$ ) were reported in 1984-2009. . However, JE reemerged in 2010 (26 cases), and the annual number of confirmed cases peaked in 2015 (40 cases). ${ }^{9}{ }^{14)}$ In 2010-2015, 129 JE cases were reported in Korea. The median patient age was 53 years, and patients $<19$ years of age accounted for only 3.1\% of cases. Most of the cases $(84.5 \%)$ occurred during summer, peaking between August and October, suggesting a temporal association with mosquito vector activity. The cases were reported mostly from metropolitan areas, including Seoul and Gyeonggi Province, followed by 


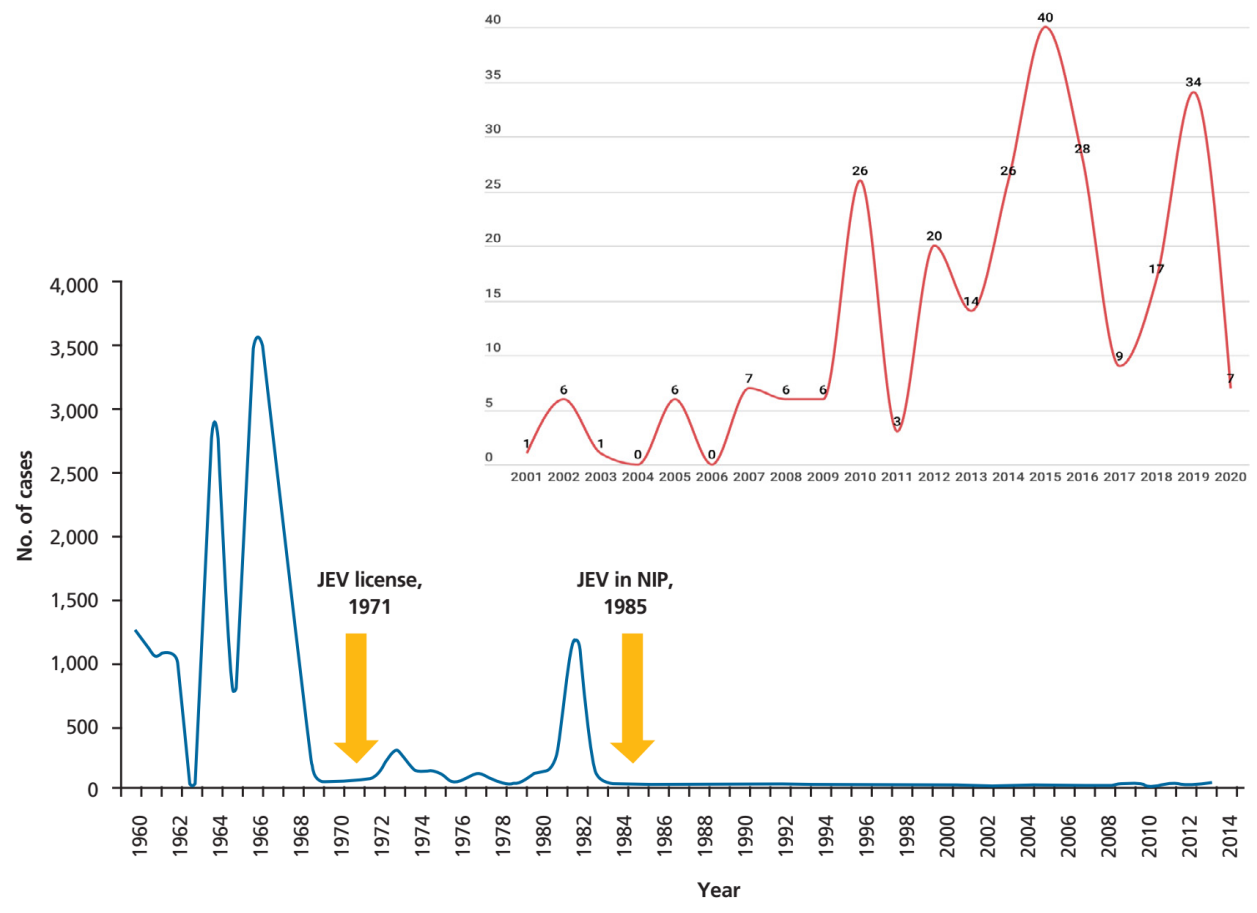

Fig. 2. Annual numbers of Japanese encephalitis cases, 1960-2020. JEV, Japanese encephalitis virus vaccine; NIP, national immunization program. Adapted from Korea Disease Control and Prevention Agency. Infectious diseases surveillance yearbook 2019. ${ }^{14)}$ Korea Disease Control and Prevention Agency. Infectious disease portal [Internet]. Cheongju, Korea: Korea Disease Control and Prevention Agency; 2020 [cited 2022 Jan 20]. Available from: https:// www.kdca.go.kr/npt/biz/npp/ist/simple/simplePdStatsMain.do?icdCd=NC0003\&icdgrpCd=03.

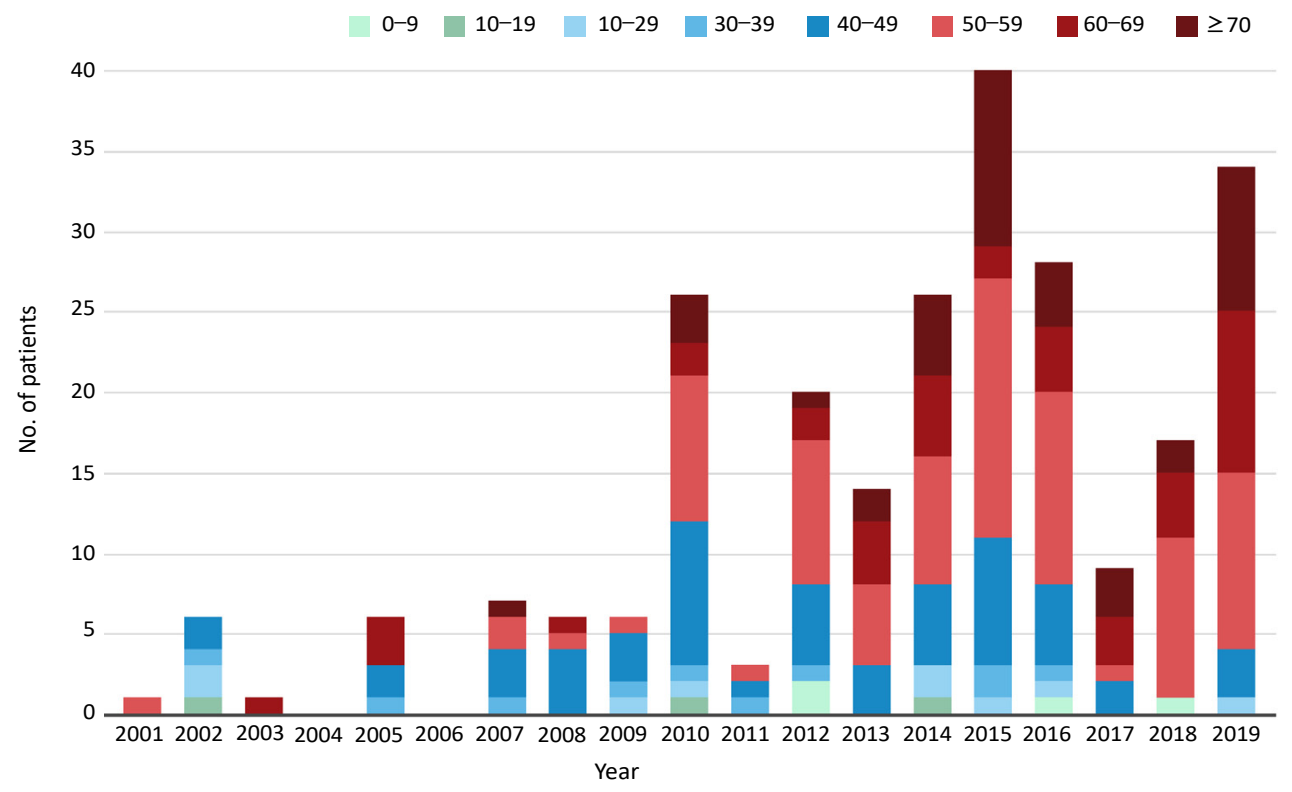

Fig. 3. Age distribution of cases of Japanese encephalitis in Korea, 2001-2019. Adapted from Korea Disease Control and Prevention Agency. Infectious diseases surveillance yearbook 2019. ${ }^{14)}$

Chungcheong, Gyeongsang, and Gangwon Provinces. ${ }^{14)}$ Recent JE cases have occurred predominantly in unvaccinated adults aged 40 years or older. The age distribution of JE cases reported in Korea in 2001-2019 is shown in Fig. 3.

\section{Japanese encephalitis vaccine}

The mouse brain-derived inactivated Japanese encephalitis vaccine (JE-MB) based on the Nakayama strain has been the dominant vaccine used throughout Asia. At present, a liveattenuated virus vaccine, recombinant chimeric virus vaccine 
(JE-CV), and inactivated Vero cell-derived JE vaccine (JE-VC) are available as second-generation JE vaccines and alternatives to JE-MB. ${ }^{1,15)}$

In Korea, JE-MB based on the Nakayama strain was first introduced in 1967, with a vaccine coverage rate of $<5 \%$ in the 1970s. ${ }^{4)}$ However, the JE epidemic in 1982-1983 prompted a mass immunization program for children aged 3-15 years. The series consisted of 3 doses of primary vaccine, with annual boosters until 15 years of age. Since 1984, when JE vaccine coverage reached almost $90 \%$, the incidence of JE has decreased from $>18.5 / 100,000$ in 1964 to $<0.02 / 100,000 .^{4)}$ A liveattenuated virus vaccine based on the SA 14-14-2 strain has also been on the market since the late 1990s in Korea and was included as an NIP vaccine in 2014. ${ }^{7,15,16)}$ JE-VC based on the Beijing-1 strain was also included in the NIP in 2015 and substituted for the existing JE-MB (Table 1). Currently, the JE-VC (Greencross cell-culture Japanese encephalitis vaccine and Boryung cellculture Japanese encephalitis vaccine), a live-attenuated virus vaccine (CD.JEVAX, Chengdu Institute of Biological Products, Sichuan, China), and JE-CV (IMOJEV, Sanofi Pasteur, Lyon, France) are available to prevent JE in Korea (Table 2). ${ }^{15-17)}$

The immunization schedule for JE differs among nations (Table 3). Primary vaccination starts at the age of 12 months in Thailand, 15 months in Taiwan, 36 months in Japan, and 12-23 months in Korea. ${ }^{1)}$ In Korea, the mandatory vaccination program targeted all children aged 3-15 years following the epidemic in
1982-1983. The series consisted of 3 doses of primary vaccine with annual boosters until 15 years of age. In 1994, several cases of severe anaphylactic reactions and neurological illness after JE vaccination were reported. In response, the boosters were given once every 2 years since 1995 . The current revised schedule of inactivated JE vaccination includes a two-dose primary vaccine series at 12-24 months and 3 booster doses at 12 months after the second dose and at 6 and 12 years of age. The live-attenuated virus vaccine was administered as a 2 -dose primary series starting at 12 months with one booster dose at 6 years of age, and it is now administered with the first dose at the age of 12-23 months and the second dose at least 12 months thereafter. ${ }^{4,16}$

\section{Seroprevalence of JE-NTAbs}

Assessing the seroprevalence of JE-NTAbs among the general population is essential for providing age-specific immunity and susceptibility to the JE virus and establishing appropriate vaccination policies and other preventive measures to control it. $^{18,19)}$

There have been remarkable changes in the age-specific JE seroprevalence over time in Korea. ${ }^{18)}$ In 1946, the seropositivity rate was $51 \%$ in the 1-10 years age group, $79 \%$ in those aged $11-20$ years, and $94 \%$ in those aged 61 years or older. ${ }^{20)}$ In the 1970s, seropositivity in children and adolescents was low (10\%-

Table 1. Summary of Japanese encephalitis vaccines and changes in immunization schedule for children and adolescents in Korea

\begin{tabular}{|c|c|c|}
\hline Year & Age & Immunization schedule \\
\hline 1967 & $3-15$ years & JE-MB was first introduced in Korea \\
\hline 1984 & $3-15$ years & Mandatory annual vaccination was implemented for all children aged 3-15 years \\
\hline 1995 & $3-15$ years & Three-dose primary series at 3 years and boosters given every 2 years \\
\hline 2000 & 12 months- 12 years & Two-dose primary series at 12-24 months and 3 boosters at 12 months after the second dose, at ages 6 and 12 years \\
\hline 2012 & 12 months- 12 years & $\begin{array}{l}\text { The first dose at age } 12-23 \text { months and the second dose at least } 12 \text { months later for a live-attenuated virus vaccine. } \\
\text { One booster dose at } 6 \text { years of age was terminated as of } 2012\end{array}$ \\
\hline 2014 & 12 months- 12 years & A live-attenuated vaccine was included in NIP \\
\hline 2015 & 12 months -12 years & JE-VC was included in NIP \\
\hline
\end{tabular}

JE-MB, inactivated Japanese encephalitis vaccine; JE-VC, inactivated Vero cell-derived JE vaccine; NIP, national immunization program.

Adapted from Kwak et al. Vaccines (Basel) 2020;8:328. ${ }^{30}$ )

Table 2. Japanese encephalitis vaccines licensed for use in Korea

\begin{tabular}{|c|c|c|c|c|c|}
\hline Type of vaccine & Manufacturer & Trade name & Virus strain & Substrate & Immunization schedule \\
\hline \multirow[t]{2}{*}{ JE-MB } & Greencross & Greencross Japanese encephalitis vaccine & Nakayama & Mouse brain & \multirow{3}{*}{$\begin{array}{l}\text { Days } 0,7-30 \text { at } 12-23 \text { months of } \\
\text { age; booster after } 1 \text { year, then } \\
6,12 \text { years of age }\end{array}$} \\
\hline & $\begin{array}{l}\text { Boryung } \\
\text { Biopharma }\end{array}$ & $\begin{array}{l}\text { Boryung Japanese encephalitis vaccine } \\
\text { Boryung Japanese encephalitis vaccine PFS }\end{array}$ & & & \\
\hline$J E-V C$ & $\begin{array}{l}\text { Boryung } \\
\text { Biopharma }\end{array}$ & $\begin{array}{l}\text { Boryung cell-culture Japanese encephalitis vaccine } \\
\text { Greencross cell-culture Japanese encephalitis } \\
\text { vaccine }\end{array}$ & Beijing-1 & Vero cells & \\
\hline LJEV & Glovax & CD.JEVAX & SA-14-14-2 & PHK cells & \multirow{2}{*}{$\begin{array}{l}\text { 1st dose at } 12-23 \text { months of } \\
\text { age; } 2 \text { nd dose } 12 \text { months after } \\
\text { 1st dose }\end{array}$} \\
\hline JE-CV & Sanofi Pasteur & IMOJEV & $\begin{array}{l}\text { SA14-14-2/ } \\
\text { yellow fever } \\
17 D\end{array}$ & Vero cells & \\
\hline
\end{tabular}

$\mathrm{JE}-\mathrm{CV}$, recombinant chimeric virus vaccine; JE-MB, inactivated Japanese encephalitis vaccine; JE-VC, inactivated Vero cell-derived Japanese encephalitis vaccine; LJEV, live-attenuated Japanese encephalitis vaccine; PHK, primary hamster kidney.

a) JE-MB is not currently in use and has been replaced by JE-VC.

Adapted from the Korean Pediatric Society. Japanese encephalitis vaccines. In: Kim JH, editor. Immunization guideline. 9th ed. ${ }^{16)}$ 
Table 3. Status of Japanese encephalitis vaccination schedules for children and adolescents in high-risk countries

\begin{tabular}{|c|c|c|c|c|}
\hline Country & Type of vaccine & Schedules & Entire country & Comments \\
\hline Cambodia & LJEV & 9 Months & Yes & \\
\hline \multirow[t]{2}{*}{ China } & IJEV & 8 Months, $+7-10$ days, 2,6 years & No & \\
\hline & LJEV & 8 Months, 2 years & Yes & \\
\hline \multirow[t]{2}{*}{ India } & IJEV & 9-12, 16-24 Months & No & \\
\hline & LJEV & 9-12, 16-24 Months & No & \\
\hline Indonesia & LJEV & 10 Months & No & Only 9 districts at Bali Province \\
\hline Japan & IJEV & 36,37 Months, 4,9 years & Yes & \\
\hline Laos & LJEV & 9 Months & Yes & \\
\hline Malaysia & LJEV & 9, 21 Months & No & Sarawak state only \\
\hline Myanmar & LJEV & 9 Months & Yes & \\
\hline Nepal & LJEV & 12 Months & Yes & \\
\hline \multirow[t]{2}{*}{ Republic of Korea } & IJEV & $12-23$ Months, $+7-30$ days, +12 months, 6,12 years & Yes & \\
\hline & LJEV & 12-23 Months, +12 months & Yes & \\
\hline Sri Lanka & LJEV & 1 Year & Yes & \\
\hline Taiwan & IJEV & 15,27 Months & Yes & \\
\hline Thailand & LJEV & $1,2.5$ Years & Yes & \\
\hline Viet Nam & IJEV & 12 Months, +2 weeks, 2 years & Yes & \\
\hline
\end{tabular}

IJEV, inactivated Japanese encephalitis vaccine; LJEV, live-attenuated Japanese encephalitis vaccine.

Adapted from WHO vaccine-preventable diseases: a monitoring system. 2020 global summary, Last updated 15 July 2020 (data as of 12 October 2020 ) [Internet]. Geneva (Switzerland): World Health Organization; 2020 [cited 2022 Jan 20]. Available from: https://apps.who.int/immunization_monitoring/ globalsummary/countries?countrycriteria\%5Bcountry\%5D\%5B\%5D=KOR.

$59 \%)^{21-26)}$ Seropositivity in this group increased to $90 \%-92 \%$ in 1984-198527) and increased further to $98 \%$ in 2012. ${ }^{28)}$ In contrast, seropositivity among adults has remained high. In a study in 2010 of adults aged 30-69 years in 10 provinces, the overall seropositive rate was $98.1 \%$ using the plaque reduction neutralization test (PRNT), and no age-specific difference was found. ${ }^{\text {) }}$ In another recent study conducted in 2012 using a pseudotyped virus (PV) assay, the seropositive rate exceeded $80 \%$ for the 30-49 years age group, 75\%-80\% for the 50-69 years age group, and $60 \%$ for the $>70$ years age group. ${ }^{19}$ )

The 2 most recent studies used the PRNT and PV assays to measure NTAbs to the JE virus, respectively. These assays use the neutralization titer expressed as the maximum serum dilution yielding a 50\% reduction in virus, and titers of $\geq 1: 10$ in the PRNT and $\geq 1: 50$ in the PV assay were considered seropositive. ${ }^{6,19)}$ Although a close correlation was shown between the titers determined by the PRNT and the PV assay, ${ }^{19,29)}$ differences in assay type and other environmental factors such as residences, sanitary conditions, occupations, and vaccination status may have contributed to the interstudy differences. ${ }^{19)}$ Nevertheless, the results of these studies revealed no age-specific differences in the seroprevalence of JE, and appropriate levels of immunity to JE were maintained for all age groups in Korea.

On the other hand, seropositivity prevalence declined as age increased, and a relatively low seropositive rate was observed in middle-aged adult groups in Japan ${ }^{11)}$ and Taiwan, ${ }^{12,13)}$ where the vaccination policy spanned 50 years. In a Japanese study conducted in 2004, the 25-64 years and 70+ years age groups had seropositivity rate of 20\%-70\%, and the rate was the lowest for those aged 45-49 years. This age group was not vaccinated against JE, nor was it naturally infected at a high rate as with the elderly population. ${ }^{11)}$ In Taiwan, a similar pattern of the lowest seropositivity rate (54\%) was observed among adults born between 1963 and 1975. This population generally received 2 or three doses of the vaccine and was administered the last booster dose more than 20 prior. ${ }^{12)}$ High seropositive rates were observed in the oldest unvaccinated population (86\%) and in the youngest population born between 1981 and 1986, who received 4 doses 10-15 years prior (74\%). In both countries, a relatively low JE seroprevalence $(<50 \%)$ was observed in several age groups: those aged 30-59 years in Japan in 2004 ${ }^{11)}$ and those aged 27-39 years in Taiwan in 2002. ${ }^{12)}$ In contrast with other Asian countries, a gradual decrease in JE seroprevalence was observed in the 30-59 age group, but no age group in Korea had a seropositive rate $<50 \% .{ }^{19)}$ In another recent Korean study, the overall seropositive rate was $98 \%$ in the adult population aged 30-69 years. ${ }^{6}$ ) The high seroprevalence rate in Korea may be explained by the comparative magnitude of JE epidemics and extensive vaccination programs. ${ }^{19)}$ In Korea, 3 large epidemics with 1,000-3,500 cases were reported in 1961-1968, and 1,197 cases and 40 deaths were reported in the latest epidemic in 1982. ${ }^{4)}$ The repeated and large JE epidemics occurring within a short period may have resulted in the long-term maintenance of neutralizing antibodies in a high percentage of the elderly unvaccinated population in Korea. Furthermore, the annual mandatory vaccination program for all children aged 3-15 years introduced in the 1980s could have contributed to the high seroprevalence of JE in the general Korean population. ${ }^{4,6)}$

The revised JE immunization schedule in Korea consisted of 2-dose primary vaccination at 12-24 months and 3 boosters. ${ }^{16}$ ) In Japan, 2-dose primary vaccination at the age of 3 years and the 2 boosters at the ages of 4 and 9-13 years are recommended. The 
third booster immunization at 14-15 years was also terminated as of 2005 since the Japanese government decided to suspend the routine vaccination with the JE-MB until a safer JE vaccine was available because of safety issues. ${ }^{11,28)}$ In Taiwan, 2-dose primary vaccination is administered at 15 months of age, and 2 booster doses are administered at 27 months of age and at elementary school entry. ${ }^{12)}$ In a recent study in Korea, antibody persistence was maintained for at least 5 years after the administration of the second JE-MB booster dose. ${ }^{30)}$ Further studies on the changes in neutralizing antibody titers over time among children vaccinated with the JE-VC are required to determine the number and timing of booster doses in Korea, where natural exposures have decreased. Continuous surveillance of the seroprevalence of JE is warranted to establish a proper immunization policy in Korea.

\section{Conclusions}

The overall incidence of JE has decreased dramatically since the implementation of the universal JE vaccination program in the 1980s. However, JE cases were becoming predominant in unvaccinated adults over 40 years of age and a shift has been noted in age distribution from children to adults.

Data from studies of the seroprevalence of JE in the general Korean population suggest that individuals are likely to be protected by the universal vaccination program introduced in the 1980s. Population immunity data over time suggest that the recent level of protection against JE is high in children and remains relatively high in adults owing to childhood vaccination or natural boosting. However, the susceptible population may increase among adults who are not vaccinated or are exposed to natural infections. Therefore, periodic nationwide surveillance of the prevalence of JE-NTAb and continuous monitoring of JE cases is required to understand the population-level immunity to $\mathrm{JE}$ and determine proper immunization policies in Korea.

See the commentary on "Importance of maintaining a high childhood vaccination rate and surveillance program against Japanese encephalitis in Korea" via https://doi.org/10.3345/ cep.2021.01557.

\section{Footnotes}

Conflicts of interest: No potential conflict of interest relevant to this article was reported.

Acknowledgments: The authors would like to thank all the members of the Korean Society of Pediatric Infectious Diseases.

\section{ORCID:}

Dong Hyun Kim @ https://orcid.org/0000-0001-9883-0229

Young Jin Hong (1) https://orcid.org/0000-0002-0878-9515

Byung Ok Kwak @ https://orcid.org/0000-0001-5527-0794

\section{References}

1. Halstead SB, Hills SL, Dubischar K. Japanese encephalitis vaccines. In: Plotkin SA, Orentein WA, Offit PA, Edwards KM, editors. Plotkin's vaccines. 7th ed. Philadelphia (PA): Elsevier, 2018:511-48.

2. Solomon T. Control of Japanese encephalitis-within our grasp? N Engl J Med 2006;355:869-71.

3. Heffelfinger JD, Li X, Batmunkh N, Grabovac V, Diorditsa S, Liyanage JB, et al. Japanese Encephalitis Surveillance and Immunization - Asia and Western Pacific Regions, 2016. MMWR Morb Mortal Wkly Rep 2017; 66:579-83.

4. Sohn YM. Japanese encephalitis immunization in South Korea: past, present, and future. Emerg Infect Dis 2000;6:17-24.

5. Sabin AB, Schlesinger RW. Japanese B encephalitis in American soldiers in Korea. Am J Hyg 1947;46:356-75.

6. Lee EJ, Cha GW, Ju YR, Han MG, Lee WJ, Jeong YE. Prevalence of neutralizing antibodies to Japanese encephalitis virus among high-risk age groups in South Korea, 2010. PLoS One 2016;11:e0147841.

7. Lee DW, Choe YJ, Kim JH, Song MK, Cho H, Bae GR, et al. Epidemiology of Japanese encephalitis in South Korea, 2007-2010. Int J Infect Dis 2012;16:448-52.

8. Campbell GL, Hills SL, Fischer M, Jacobson JA, Hoke CH, Hombach JM, et al. Estimated global incidence of Japanese encephalitis: a systematic review. Bull World Health Org 2011;89:766-74, 774A-774E.

9. Simon-Loriere E, Faye O, Prot M, Casademont I, Fall G, FernandezGarcia MD, et al. Autochthonous Japanese encephalitis with yellow fever coinfection in Africa. NEngl J Med 2017;376:1483-5.

10. Sunwoo JS, Jung KH, Lee ST, Lee SK, Chu K. Reemergence of Japanese encephalitis in South Korea, 2010-2015. Emerg Infect Dis 2016;22:18413.

11. Arai S, Matsunaga Y, Takasaki T, Tanaka-Taya K, Taniguchi K, Okabe N, et al. Vaccine preventable diseases surveillance program of Japan. Japanese encephalitis: surveillance and elimination effort in Japan from 1982 to 2004. Jpn J Infect Dis 2008;61:333-8.

12. Hsu LC, Chen YJ, Hsu FK, Huang JH, Chang CM, Chou P, et al. The incidence of Japanese encephalitis in Taiwan - a population-based study. PLoS Negl Trop Dis 2014;8;e3030.

13. Tseng HF, Tan HF, Chang CK, Huang WL, Ho WC. Seroepidemiology study of Japanese encephalitis neutralizing antibodies in southern Taiwan: a comparative study between urban city and country townships. Am J Infect Control 2003;31:435-40.

14. Korea Centers for Disease Control and Prevention. Infectious diseases surveillance yearbook 2019. Cheongju (Korea): Korea Centers for Disease Control and Prevention, 2020.

15. Yun KW, Lee HJ, Park JY, Cho HK, Kim YJ, Kim KH, et al. Long-term immunogenicity of an initial booster dose of an inactivated, Vero cell culture-derived Japanese encephalitis vaccine (JE-VC) and the safety and immunogenicity of a second JE-VC booster dose in children previously vaccinated with an inactivated, mouse brain-derived Japanese encephalitis vaccine. Vaccine 2018;36:1398-404.

16. The Korean Pediatric Society. Japanese encephalitis vaccines. In: Kim $\mathrm{JH}$, editor. Immunization guideline. 9th ed. Seoul (Korea): The Korean Pediatric Society, 2018:186-202.

17. Cha SH. The history of vaccination and current vaccination policies in Korea. Clin Exp Vaccin Res 2012;1:3-8.

18. Choe YJ, Taurel AF, Nealon J, Seo HS, Kim HS. Systematic review of seroepidemiological studies on Japanese encephalitis in the Republic of Korea. Int J Infect Dis 2018;67:14-9.

19. Kwak BO, Kwon YS, Hong YJ, Nahm CH, Jang W, Uh Y, et al. Seroprevalence of neutralizing antibodies against Japanese encephalitis virus among adolescents and adults in Korea: a prospective multicenter study. Vaccines (Basel) 2020;8:328.

20. Deuel RE Jr, Barwell MB, Matumoto M, Sabain AB. Status and significance of inapparent infection with virus of Japanese B encephalitis in Korean and Okinawa in 1946. Am J Hyg 1950;51:13-20.

21. Kim KH. Recent epidemiological features of Japanese encephalitis in the 
Republic of Korea. Korean J Infect Dis 1974;6:83-8.

22. Kim SO, Lee YJ, Jung BK, Lee HW. The distribution of hemagglutination inhibition antibody for Japanese encephalitis in residents of Seoul areas. Choeshin Ui-hak 1976;19:21-6.

23. Lee YT, Lee CH. Serological study on Japanese encephalitis in Koreans and fowls, 1975. Korean J Infect Dis 1976;8:75-82.

24. Lee YT, Lee CH. The distribution of hemagglutination inhibition antibodies for Japanese encephalitis virus against the Koreas 1976. J Korean Soc Microbiol 1977;12:51-6.

25. Lee $\mathrm{CH}$, Ko KK. The distribution of hemagglutination inhibition antibodies for Japanese encephalitis virus in Korea $(1977,1978)$. Choeshin Ui-hak 1979:113-9.

26. Lee CH, Lee YT, Ko KJ, Moon KS, Kim OJ. The distribution of hemagglutination inhibition antibodies for Japanese encephalitis virus in Koreans 1979. Korean J Virol 1980;10:65-9.

27. Lee YT, Youm BJ. A hemagglutination inhibition antibody test for Japanese encephalitis virus among the Koreans, 1984-1985. Korean J Virol 1985;15:1-9.
28. Abe M, Okada K, Hayashida K, Matsuo F, Shiosaki K, Miyazaki C, et al. Duration of neutralizing antibody titer after Japanese encephalitis vaccination. Microbiol Immunol 2007;51:609-16.

29. Lee HJ, Min KI, Park KH, Choi HJ, Kim MK, Ahn CY, et al. Comparison of JEV neutralization assay using pseudotyped JEV with the conventional plaque-reduction neutralization test. J Microbiol 2014;52:435-40.

30. Kwak BO, Kwon YS, Hong YJ, Shin SH, Eun BW, Ahn YM, et al, Immunogenicity and safety of the third booster dose of the inactivated Japanese encephalitis vaccine in Korean. Vaccine 2021;39:1929-32.

How to cite this article: Kwak BO, Hong YJ, Kim DH. Changes in age-specific seroprevalence of Japanese encephalitis virus and impact of Japanese encephalitis vaccine in Korea. Clin Exp Pediatr 2022;65:108-14. https://doi.org/10.3345/ cep. 2020.01984 